\title{
Mössbauer study of FINEMET with different permeability
}

\author{
E. Kuzmann • S. Stichleutner • A. Sápi · Z. Klencsár • \\ M. I. Oshtrakh • V. A. Semionkin • S. Kubuki • \\ Z. Homonnay • L. K. Varga
}

Published online: 14 November 2012

(C) Springer Science+Business Media Dordrecht 2012

\begin{abstract}
Stress field and magnetic field annealed FINEMET ribbons were investigated by ${ }^{57} \mathrm{Fe}$ Mössbauer spectroscopy, magnetic and XRD methods. The change in relative areas of the 2 nd and 5 th lines in the Mössbauer spectra indicated significant variation in magnetic anisotropy due to the different annealing. High velocity resolution Mössbauer spectroscopy was also used to control the model applied for the evaluation of Mössbauer spectra. A correlation was found between the permeability and the magnetic anisotropy of the annealed FINEMET samples. This can be applied to predict production parameters of FINEMET ribbons with more favorable soft magnetic properties for technological applications.
\end{abstract}

E. Kuzmann $(\bowtie) \cdot$ A. Sápi · Z. Homonnay

Laboratory of Nuclear Chemistry, Institute of Chemistry, Eötvös University,

Budapest, Hungary

e-mail: kuzmann@ludens.elte.hu

S. Stichleutner

Centre for Energy Research, HAS, Budapest, Hungary

Z. Klencsár

Institute of Molecular Pharmacology, Research Centre for Natural Sciences, HAS, Budapest, Hungary

M. I. Oshtrakh · V. A. Semionkin

Department of Physical Techniques and Devices for Quality Control,

Ural Federal University, Ekaterinburg, Russian Federation

M. I. Oshtrakh · V. A. Semionkin

Department of Experimental Physics, Ural Federal University,

Ekaterinburg, Russian Federation

S. Kubuki

Tokyo Metropolitan University, Tokyo, Japan

L. K. Varga

Wigner Research Centre for Physics, HAS, Budapest, Hungary 
Keywords FINEMET • Nanocrystalline ribbon • Permeability •

Mössbauer spectroscopy $\cdot$ Magnetic anisotropy

\section{Introduction}

Nanocrystalline $\mathrm{Fe}_{73.5} \mathrm{Si}_{13.5} \mathrm{Nb}_{3} \mathrm{~B}_{9} \mathrm{Cu}_{1}$ FINEMET alloys are widely applied in the industry as excellent soft magnetic material due to high permeability $\left(\sim 10^{5}\right.$ at $\left.1 \mathrm{kHz}\right)$, low magnetostriction $\left(\sim 2 \times 10^{-6}\right)$, large magnetization $(\sim 1.2 \mathrm{~T})$, low coercivity $(\sim 1 \mathrm{~A} / \mathrm{m})$ and low power loss $\left(<5 \mathrm{~J} / \mathrm{m}^{3}\right)$. Production of FINEMET ribbons with more favorable soft magnetic properties for technological applications can be achieved by inducing a transversal magnetic anisotropy via stress annealing [1] or using irradiation with energetic heavy ions [2].

The aim of the present work was to investigate the correlation between the permeability and magnetic anisotropy in annealed nanocrystalline FINEMET samples. For this goal we studied the change in magnetic anisotropy via the change in relative areas of the 2nd and 5th lines in Mössbauer spectra of both stress field and magnetic field annealed FINEMET and checked the phase composition and crystal structure by XRD.

\section{Experimental}

$\mathrm{Fe}_{73.5} \mathrm{Si}_{13.5} \mathrm{Nb}_{3} \mathrm{~B}_{9} \mathrm{Cu}_{1}$ FINEMET ribbons were rapidly quenched and subsequently stress annealed at $550{ }^{\circ} \mathrm{C}$ for $1 \mathrm{~h}$ under different tensile stresses between 0 and $124 \mathrm{MPa}$, obtaining the samples with permeability between 90 and 6000. For comparison, one sample was nanocrystallized at $550{ }^{\circ} \mathrm{C} / 1 \mathrm{~h}$ and further annealed under transversal magnetic field of $160 \mathrm{kA} / \mathrm{m}$ at $450{ }^{\circ} \mathrm{C}$ for $1 \mathrm{~h}$ obtaining a permeability as high as 60000 .

The ${ }^{57} \mathrm{Fe}$ Mössbauer spectra of the FINEMET samples were taken at $295 \mathrm{~K}$ using a conventional Mössbauer spectrometer (WISSEL) in transmission geometry. The magnetic anisotropy was characterized by measuring the relative ratio of the 2 nd and 5 th lines of sextets, determining the angle $\theta$ between the directions of magnetic moment and $\gamma$-ray from the formula

$$
\frac{A_{2,5}}{A_{1,6}}=\frac{4 \sin ^{2} \theta}{3\left(1+\cos ^{2} \theta\right)}
$$

at the fixed relative ratio of $\mathrm{A}_{1,6} / \mathrm{A}_{3,4}=3$.

The $\gamma$-rays were provided by a $3 \times 10^{9} \mathrm{~Bq}{ }^{57} \mathrm{Co} / \mathrm{Rh}$ source. Isomer shifts are given relative to $\alpha$-Fe at room temperature. The Mössbauer spectra were analyzed by leastsquare fitting of Lorentzian lines by the help of the MOSSWINN code [3].

Selected spectra were also recorded in 4096 channels, with significantly less instrumental error, using an automated precision Mössbauer spectrometric system on the base of the spectrometer SM-2201 with a high velocity resolution at room temperature with moving absorber. Details and characteristics of this equipment and the system were given elsewhere [4-6].

Permeability $(\mu)$ of the samples was measured using impedance meter. 
Fig. $1{ }^{57} \mathrm{Fe}$ Mössbauer spectra, recorded at $T=295 \mathrm{~K}$ in 512 channels with conventional velocity resolution, of FINEMET samples with permeability a $\mu_{r}=170, \mathbf{b} \mu_{r}=6000$ and c $\mu_{r}=60000$

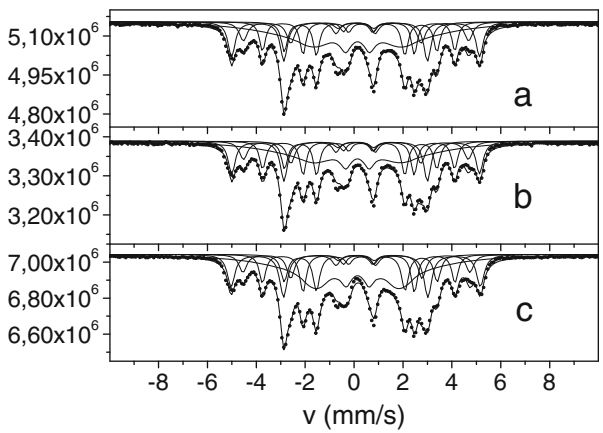

Table 1 Permeability, relative area of 2nd and 5th lines and angle of the average direction of magnetic moment with respect to the normal vector of the ribbon surface of FINEMET samples

\begin{tabular}{lrrrrrrrrc}
\hline Permeability & \multicolumn{1}{c}{90} & \multicolumn{1}{c}{130} & \multicolumn{1}{c}{170} & \multicolumn{1}{c}{840} & 1350 & 2000 & 3200 & 6000 & 60000 \\
\hline $\mathrm{A}_{2,5} / \mathrm{A}_{3,4}$ & 2.85 & 3.19 & 3.39 & 3.70 & 3.45 & 3.63 & 3.59 & 3.69 & 4.0 \\
Angle & 65.81 & 70.38 & 73.34 & 78.79 & 74.36 & 77.32 & 76.69 & 78.54 & 90 \\
\hline
\end{tabular}

Powder X-ray diffractograms of the samples were measured by a computer controlled DRON-2 X-ray diffractometer using $\mathrm{Co}_{K \alpha}$ radiation and $\beta$ filter. The evaluation of the XRD patterns was made by the EXRAY code. For identification of the phases the ASTM X-ray diffraction data were used.

\section{Results and discussion}

Typical XRD of annealed FINEMET sample reflects nanocrystalline character. The peaks belonging to $(2,2,0)$ and $(4,4,0)$ reflections of cubic Fe-Si phase with lattice parameter of $0.5669 \mathrm{~nm}$ are in good agreement with ASTM card no. 47-1114 and with the earlier results [2].

The Mössbauer spectra measured with a low velocity resolution (Fig. 1) reflect significant changes in the magnetic anisotropy via the changes in the relative areas of the 2nd and 5th lines for the samples having different permeability. We have found gradual change in the average direction of magnetic moment (from $65.8^{\circ}$ to $90^{\circ}$ with respect to the normal vector of the ribbon surface) with the change of permeability (from $\mu_{\mathrm{r}}=170$ to $\mu_{\mathrm{r}}=60000$ ). The data are shown in Table 1. Figure 2 illustrates the tendency of magnetic anisotropy dependence on the permeability. Our results are consistent with the effect of stress annealing, i.e. that higher stress field applied at annealing induces higher magnetic anisotropy [2]. On the other hand, they also help clarify the controversial data in the literature [1], which were obtained in a relatively narrow permeability interval. The detailed explanation of our findings will be published elsewhere.

The Mössbauer spectra of all samples were decomposed into 5 sextets $(3$ sextets corresponding to Fe having 4, 5 and 6 nearest Fe neighbors in sublattice A, 1 sextet corresponding to $\mathrm{Fe}$ in sublattice $\mathrm{B}$ in which $\mathrm{Fe}$ has 7 or 8 nearest Fe neighbors in Fe-Si phase and 1 sextet assigned to $\mathrm{Fe}$ in amorphous phase) similarly to the case of previous works on the annealed FINEMET $[1,2,7]$. Table 2 shows hyperfine fields of 
Fig. 2 Dependence of angle of the average direction of magnetic moment on the permeability of FINEMET samples

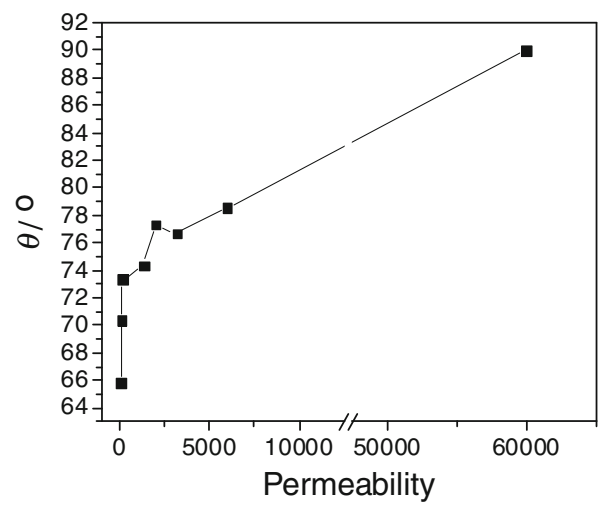

Table 2 Average hyperfine field parameters of spectral components of FINEMET samples

\begin{tabular}{lllll}
\hline $\mathrm{A}_{2,5} / \mathrm{A}_{3,4}$ & 3.39 & 3.63 & 4.0 & Fe site \\
\hline $\mathrm{B}_{1}[\mathrm{~T}]$ & $31.48(0.01)$ & $31.46(0.01)$ & $31.63(0.01)$ & $\mathrm{D}+\mathrm{A}_{8}+\mathrm{A}_{7}$ \\
$\mathrm{~B}_{2}[\mathrm{~T}]$ & $28.58(0.03)$ & $28.59(0.02)$ & $28.79(0.02)$ & $\mathrm{A}_{6}$ \\
$\mathrm{~B}_{3}[\mathrm{~T}]$ & $24.41(0.01)$ & $24.39(0.01)$ & $24.43(0.01)$ & $\mathrm{A}_{5}$ \\
$\mathrm{~B}_{4}[\mathrm{~T}]$ & $19.37(0.01)$ & $19.35(0.01)$ & $19.42(0.01)$ & $\mathrm{A}_{4}$ \\
$\mathrm{~B}_{5}[\mathrm{~T}]$ & $19.01(0.19)$ & $19.02(0.13)$ & $18.26(0.10)$ & Amorphous \\
\hline
\end{tabular}

Fig. $3{ }^{57} \mathrm{Fe}$ Mössbauer spectra, recorded with a high velocity resolution spectrometer in 4096 channels, of FINEMET samples with permeability a $\mu_{r}=1350$ and b $\mu_{r}=6000 . T=295 \mathrm{~K}$

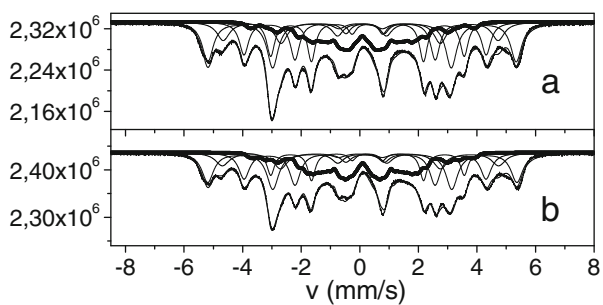

these sextets for selected samples. In all samples the hyperfine fields of the individual components were found to be practically the same. This reflects that, besides the considerable changes found in the magnetic anisotropy, no other significant change in the individual iron microenvironments can be observed at the different stress or field annealing. The reliability of the determination of magnetic anisotropy by the Mössbauer method is enhanced, since the high velocity resolution Mössbauer spectra (Fig. 3) of the FINEMET samples could also be roughly resolved into the 4 sextets of Fe-Si phase, but 3 sextets for the amorphous phase, when the relative areas of the 2 nd and 5 th lines were in a fairly good agreement with those obtained with the low velocity resolution measurement for the corresponding samples. The detailed analysis of the high velocity resolution spectra will be published in the near future. 


\section{Conclusion}

A new correlation of magnetic anisotropy, obtained from relative areas of the 2 nd and 5th lines in Mössbauer spectra, with the permeability has been found in annealed FINEMET samples in a wide range of permeability (from $\mu_{\mathrm{r}}=170$ to $\mu_{\mathrm{r}}=60000$ ). The correlation found can be applied to predict preparation parameters to produce FINEMET ribbons with more favorable soft magnetic properties for technological applications.

Acknowledgements The research was supported by grants of the Hungarian Science Foundation (OTKA K68135 and K100424) and by the Hungarian Academy of Sciences under project no. EAI2009/003-10030. M.I.O. and V.A.S. were supported by the basic financing from the Ministry of Science and Education of Russian Federation.

\section{References}

1. Kane, S.N., Alves, F., Gupta, A., Gupta, P., Varga, L.K.: Hyperfine Interact. 191, 377 (2009)

2. Kuzmann, E., Stichleutner, S., Sápi, A, Varga, L.K., Havancsák, K., Skuratov, V., Homonnay, Z., Vértes, A.: Hyperfine Interact. 207, 73 (2012)

3. Klencsár, Z., Kuzmann, E., Vértes, A.: J. Radioanal. Nucl. Chem. 210, 105 (1996)

4. Oshtrakh, M.I., Semionkin, V.A., Milder, O.B., Novikov, E.G.: J. Radioanal. Nucl. Chem. 281, 63 (2009)

5. Semionkin, V.A., Oshtrakh, M.I., Milder, O.B., Novikov, E.G.: Bull. Rus. Acad. Sci., Phys. 74, 416 (2010)

6. Oshtrakh, M.I., Semionkin, V.A.: Spectrochim. Acta, Part A: Mol. Biomol. Spectrosc. (2012). doi:10.1016/j.saa.2012.03.020

7. Boreggo, J.M., Conde, A., Pena-Rodríguez, V.A., Greneche, J.M.: Hyperfine Interact. 131, 67 (2000) 